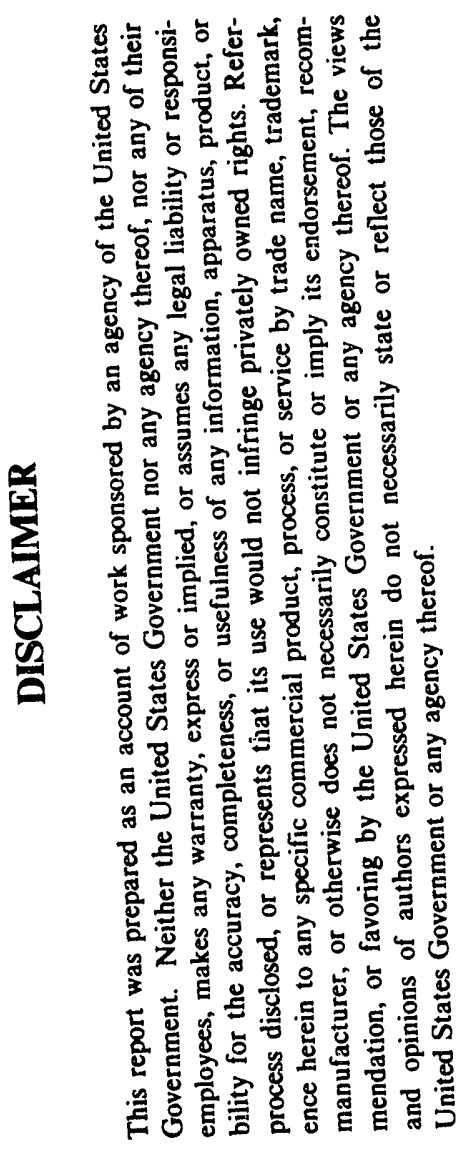

\title{
TEVATRON STUDIES REPORT
}

\author{
G. Jackson, D. McConnell, and B. Fellenz \\ Fermi National Accelerator Laboratory
}

E. Raka and S.P. Yamin

Brookhaven National Laboratory

April 23, 1993

\section{ALTERNATING GRADIENT SYNCHROTRON DEPARTMENT \\ BROOKHAVEN NATIONAL LABORATORY \\ ASSOCIATED UNIVERSITIES, INC. \\ UPTON, LONG ISLAND, NEW YORK}

UNDER CONTRACT NO. DE-AC02-76CH00016 WITH THE UNITED STATES DEPARTMENT OF ENERGY 
BNL-

UC-414

AGS/AD/93-4

INFORMAL

\section{TEVATRON STUDIES REPORT}

G. Jackson, D. McConnell, and B. Fellenz

Fermi National Accelerator Laboratory

E. Raka and S.P. Yamin

Brookhaven National Laboratory

April 23, 1993

ALTERNATING GRADIENT SYNCHROTRON DEPARTMENT

BROOKHAVEN NATIONAL LABORATORY

ASSOCIATED UNIVERSITIES, INC. UPTON, LONG ISLAND, NEW YORK

UNDER CONTRACT NO. DE-AC02-76CH00016 WITH THE UNTTED STATES DEPARTMENT OF ENERGY 
Accelerator Division

Alternating Gradient Synchrotron Department

BROOKHAVEN NATIONAL LABORATORY

Upton, New York 11973

Accelerator Division

Technical Note

AGS/AD/Tech. Note No. 369

\title{
TEVATRON STUDIES REPORT
}

\author{
G. Jackson, D. McConnell, and B. Fellenz \\ Fermi National Accelerator Laboratory \\ E. Raka and S.P. Yamin \\ Brookhaven National Laboratory
}

December 3, 1992

\section{Introduction}

On Wednesday, July 24, 1991, we studied the effectiveness of "constant amplitude" transverse damping at the Fermilab Tevatron. In this mode of damping, whenever a bunch's displacement exceeds a specified threshold, a constant (usually maximum) amplitude correction pulse is applied to the damper kicker. This is in contrast to the "linear" mode, where the kick is proportional to the displacement.

\section{Procedure}

The beam was injected into the Tevatron with vertical displacement, so as to induce vertical betatron oscillations. Figure 1 shows the output of one of the pick-up electrodes (PUEs) for 1024 successive turns. The modulation is caused by the changing coherence of the oscillations of particles of different momenta (and tune because of the chromaticity) around the synchrotron oscillation cycle. Decoherence is responsible for the damping of the oscillations. If we assume that, then the amplitude is given by $A=A_{0} \exp [-($ turn $\$) / k], k=2661$ tums.

We next studied the properties of various damping transfer functions. These are shown in Figures 2a-2d. In all cases the abscissa represents displacement from the "closed orbit" in millimeters and the ordinate the voltage applied to the kicker electrodes ( $\pm 1000 \mathrm{~V}$ maximum).

First we studied linear damping (Figure 2a). The results are shown in Figure 3. Here, we get $\mathrm{k}=1089$ turns. 
For the mixed constant-amplitude and linear transfer function shown in Figure $2 b$, we got the results shown in Figure 4. The fit to the damping constant gives $k:=739$ turns.

A constant amplitude transfer function with the threshold set at $\pm 2.5 \mathrm{~mm}$ is shown in Figure $2 \mathrm{c}$ and the results are plotted in Figure 5. $\mathrm{k}=1002$ turns.

Constant-amplitude damping with a $\pm 1 \mathrm{~mm}$ transfer function threshold is shown in Figure 2d. These results are given in Figure 6. $k=797$ turns.

\section{$\underline{\text { Conclusions }}$}

We believe that we have shown that constant-amplitude damping can be as effective as linear damping in the Tevatron. However, since this machine operates in a regime in which resistive wall instabilities are not present and where the Landau damping is sufficient, the present studies do not represent an adequate test. We suggest extending these tests to the Main Ring, where there is a resistive wall instability. Unfortunately, this will require modifying more than software.

$$
\text { mvh }
$$


$-3-$

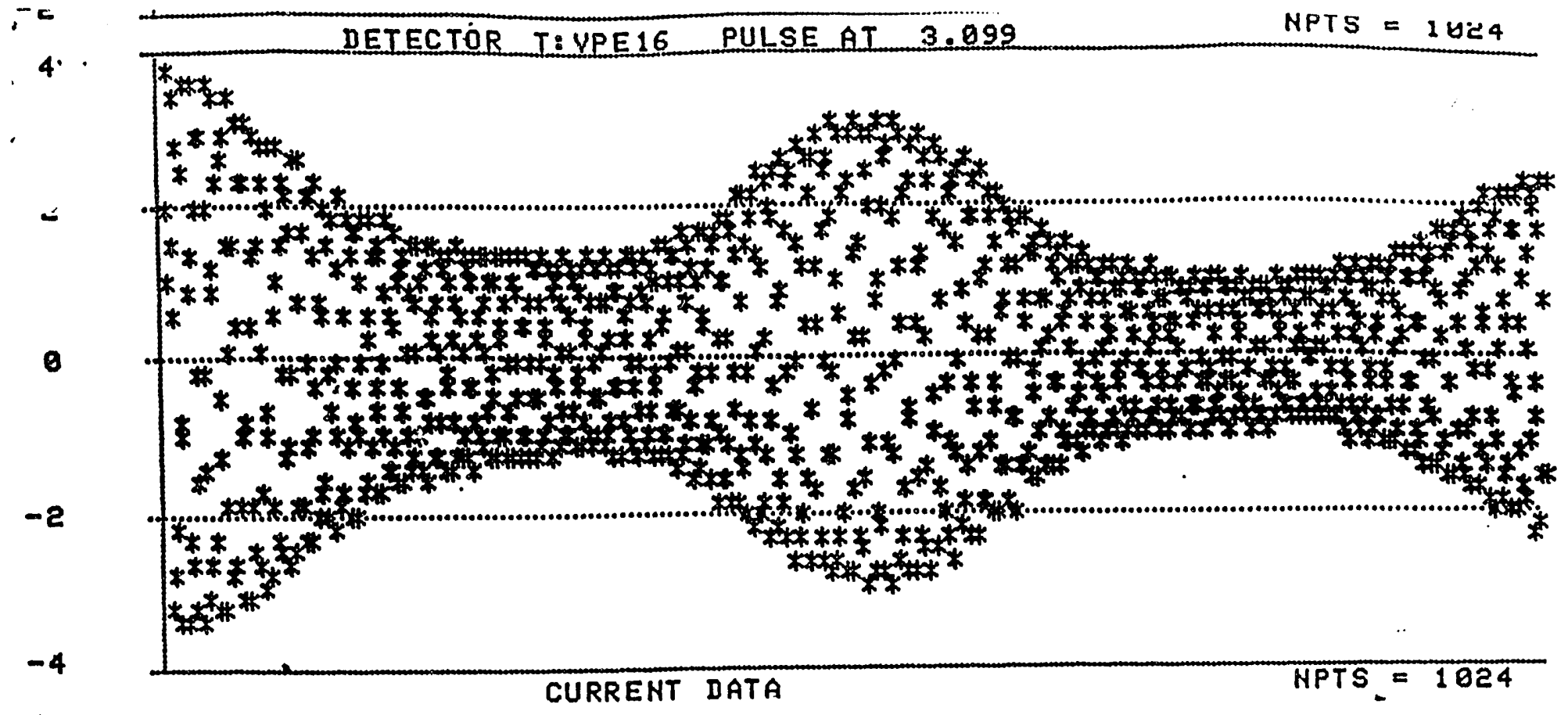

Figure 1 - No damping
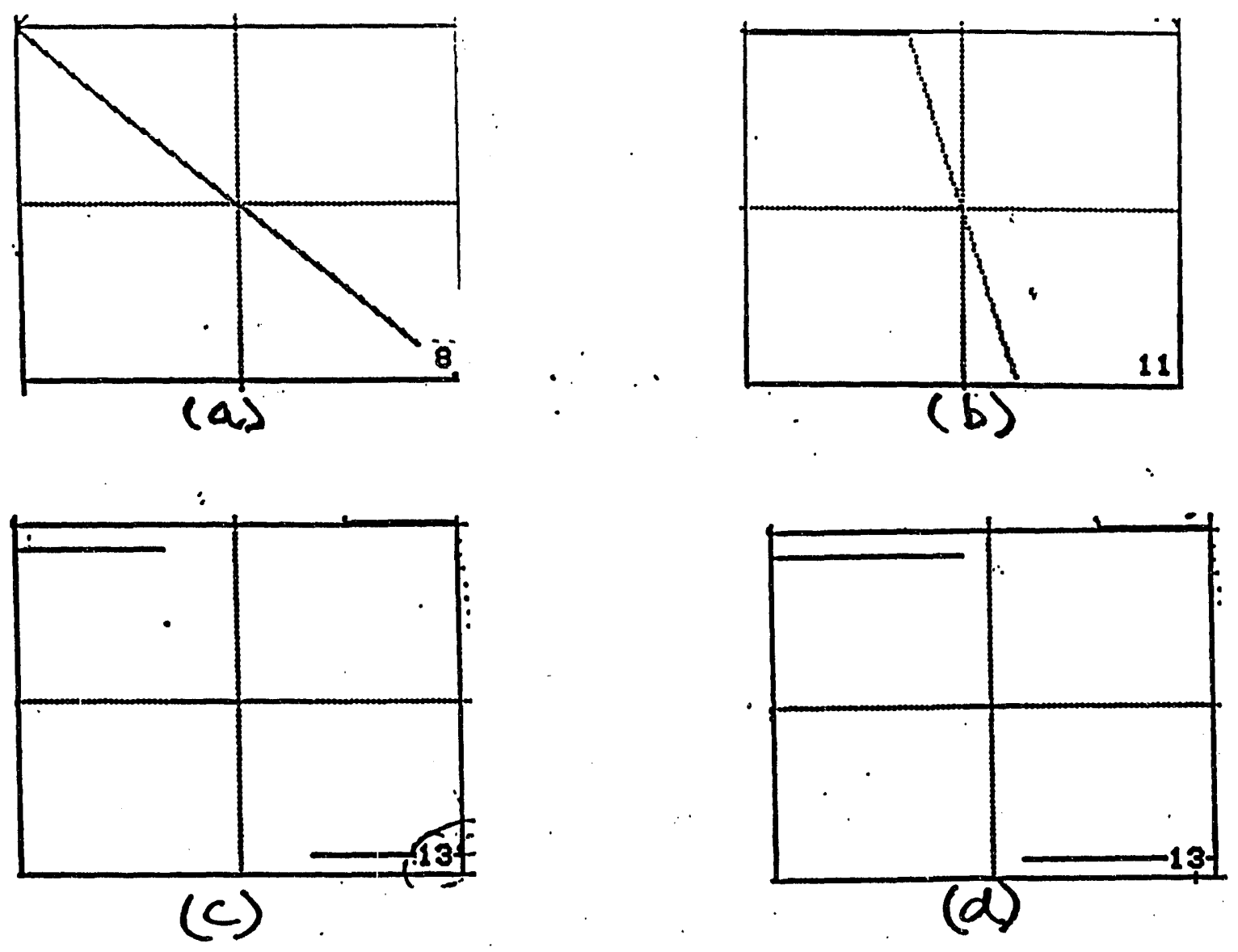

Figure 2 - Transfer functions 
$-4-$

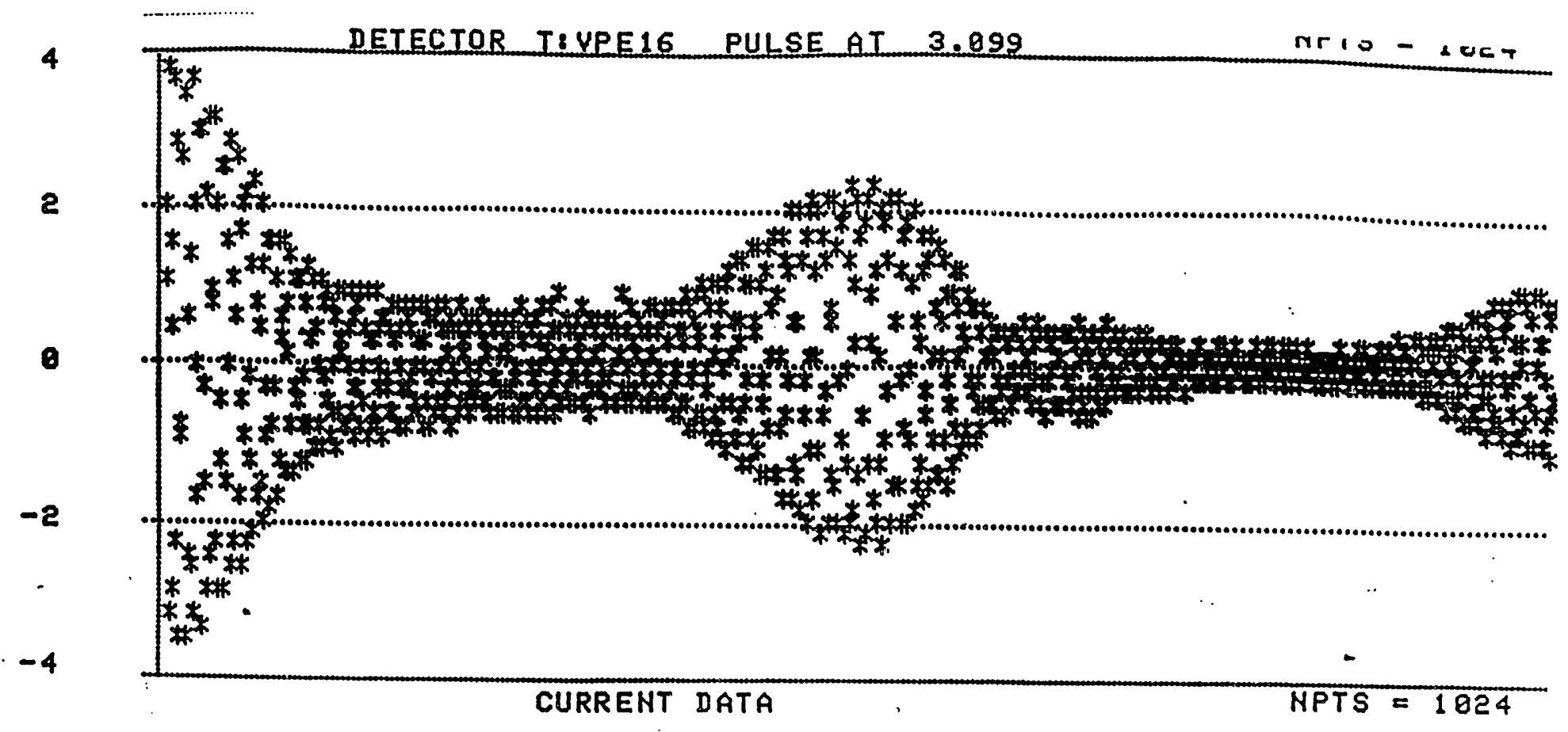

Figure- linear damping

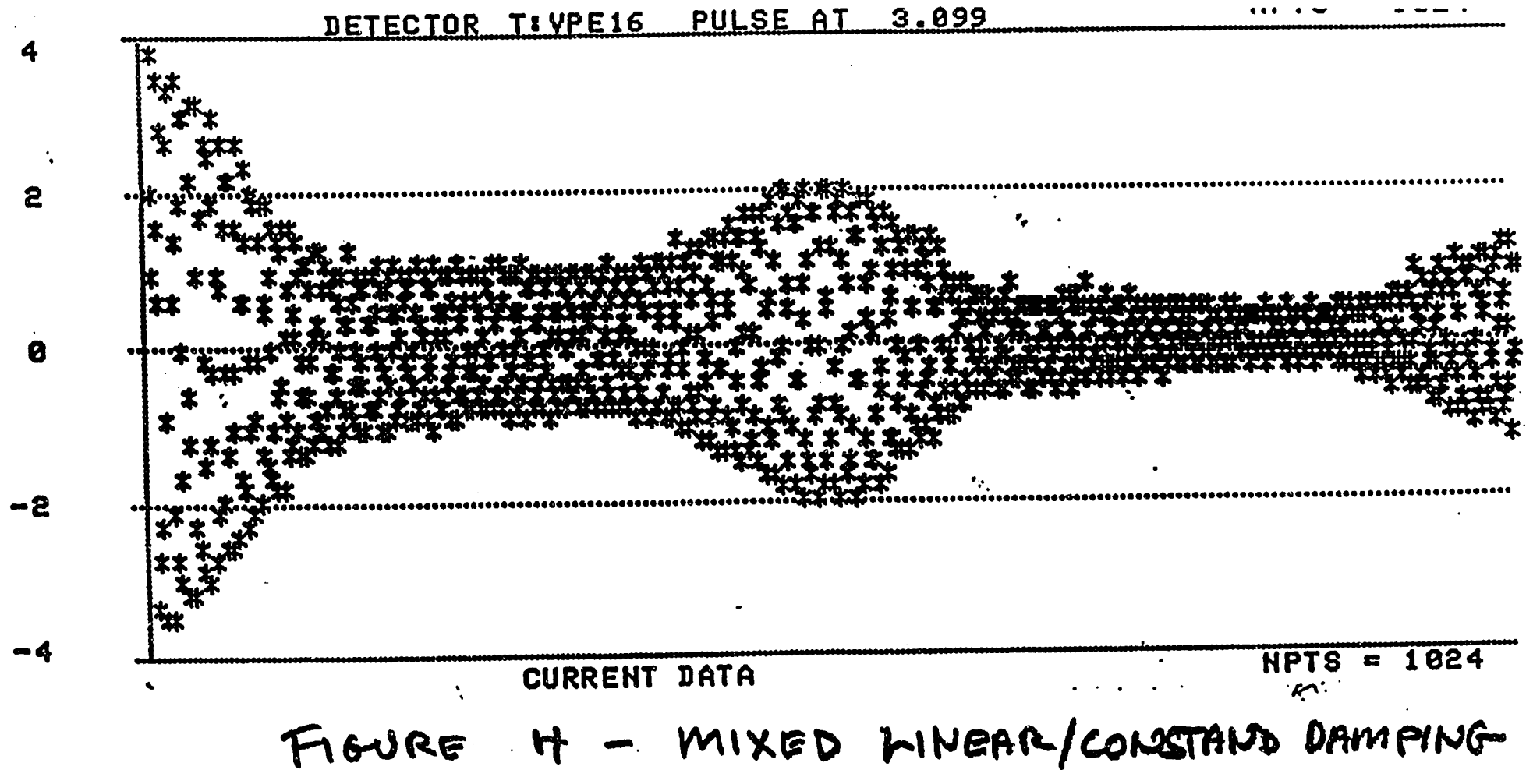




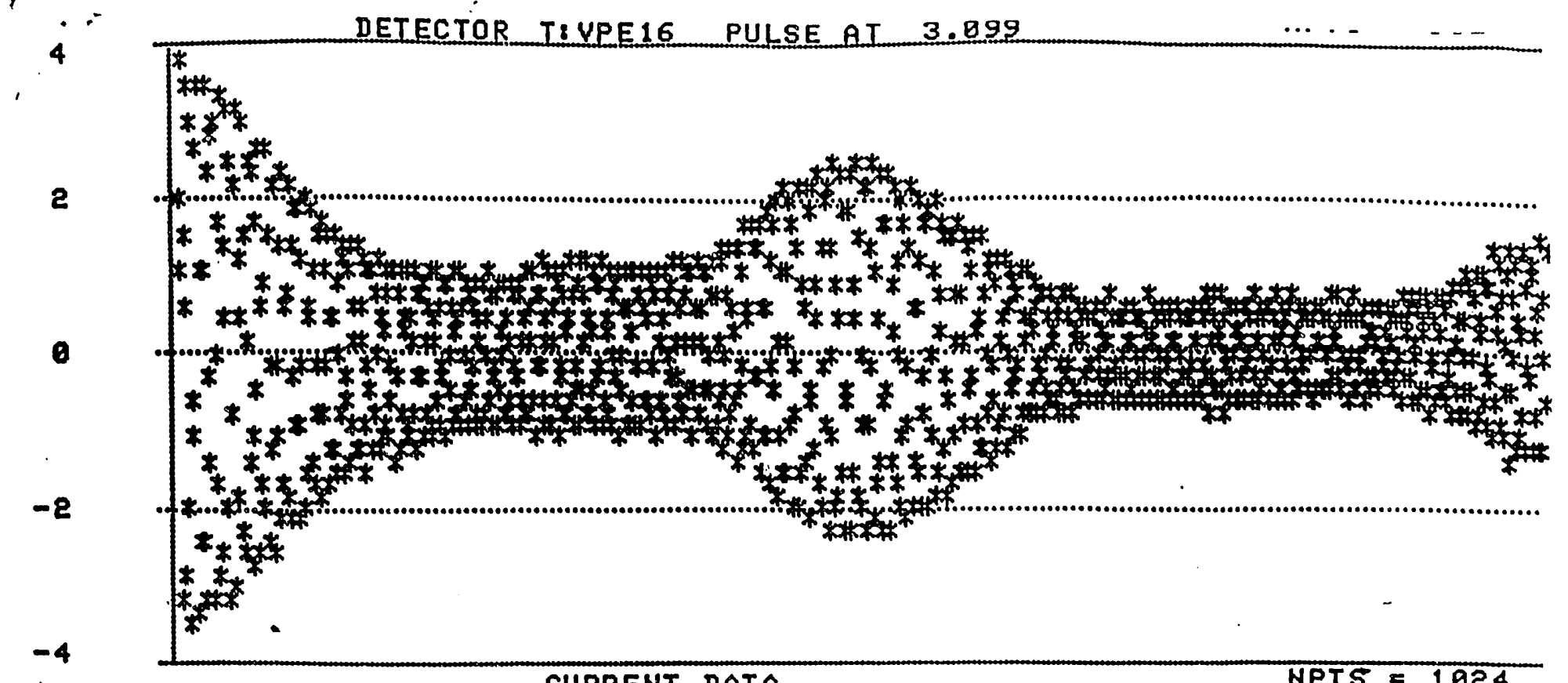

CURRENT DATA

Figure 5-Constant amplatude ( $125 \mathrm{~mm}$ ) Damang

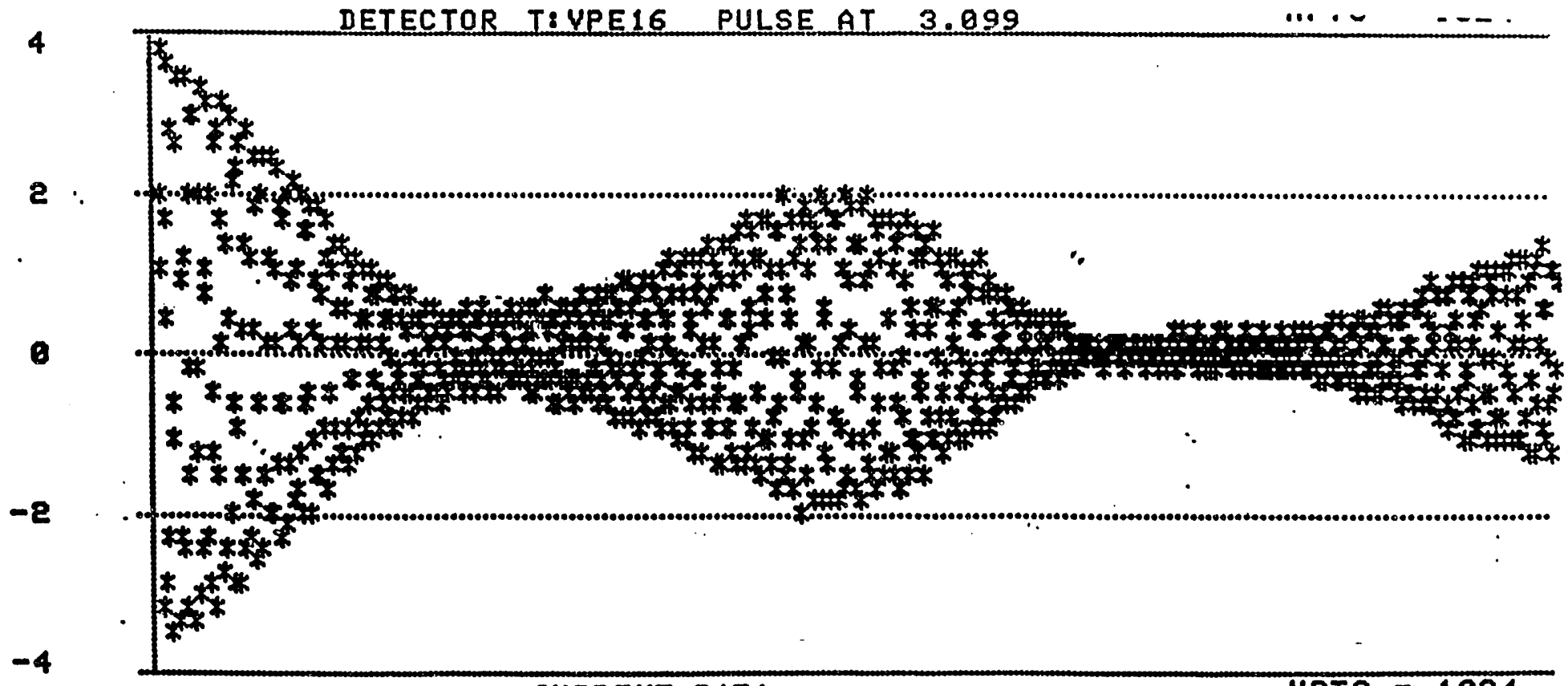
CURRENT DATA

FIGORG 6 - CONSTAND AMPLITUDE ( $( \pm \mathrm{mm})$ DAMPING 

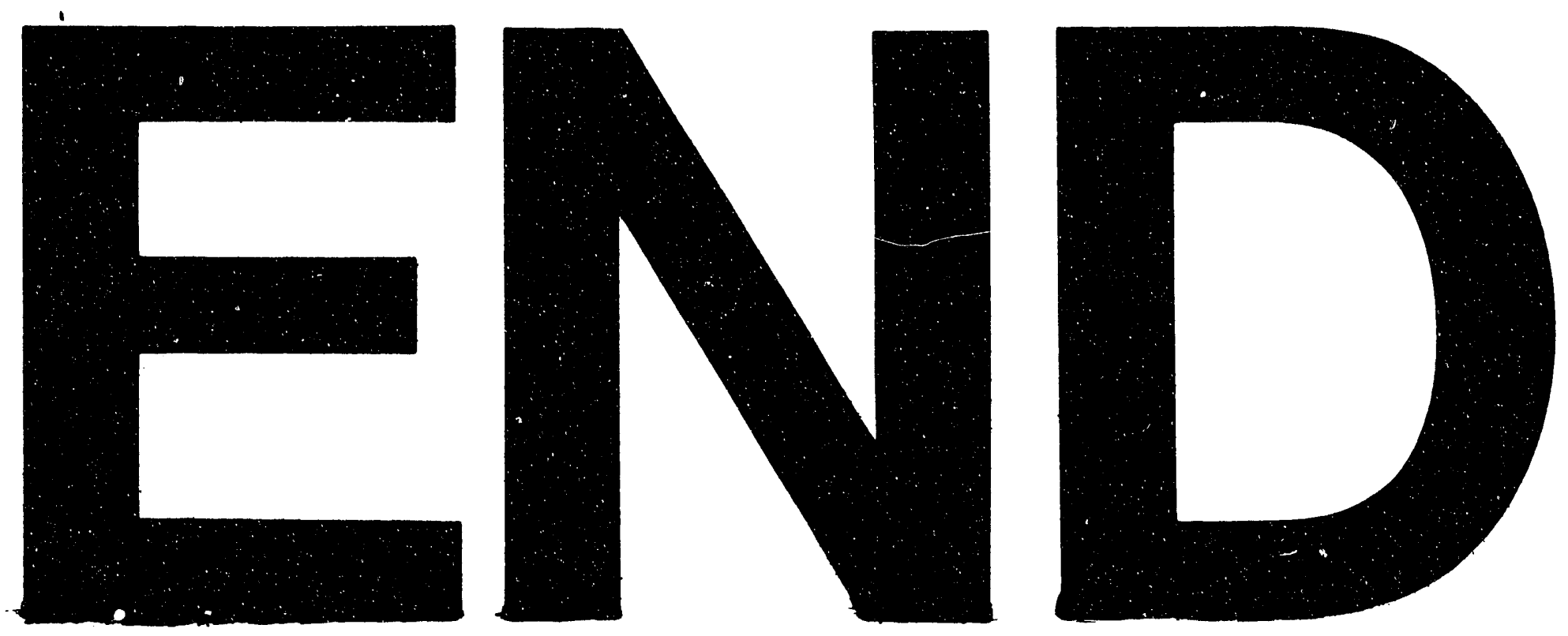

7
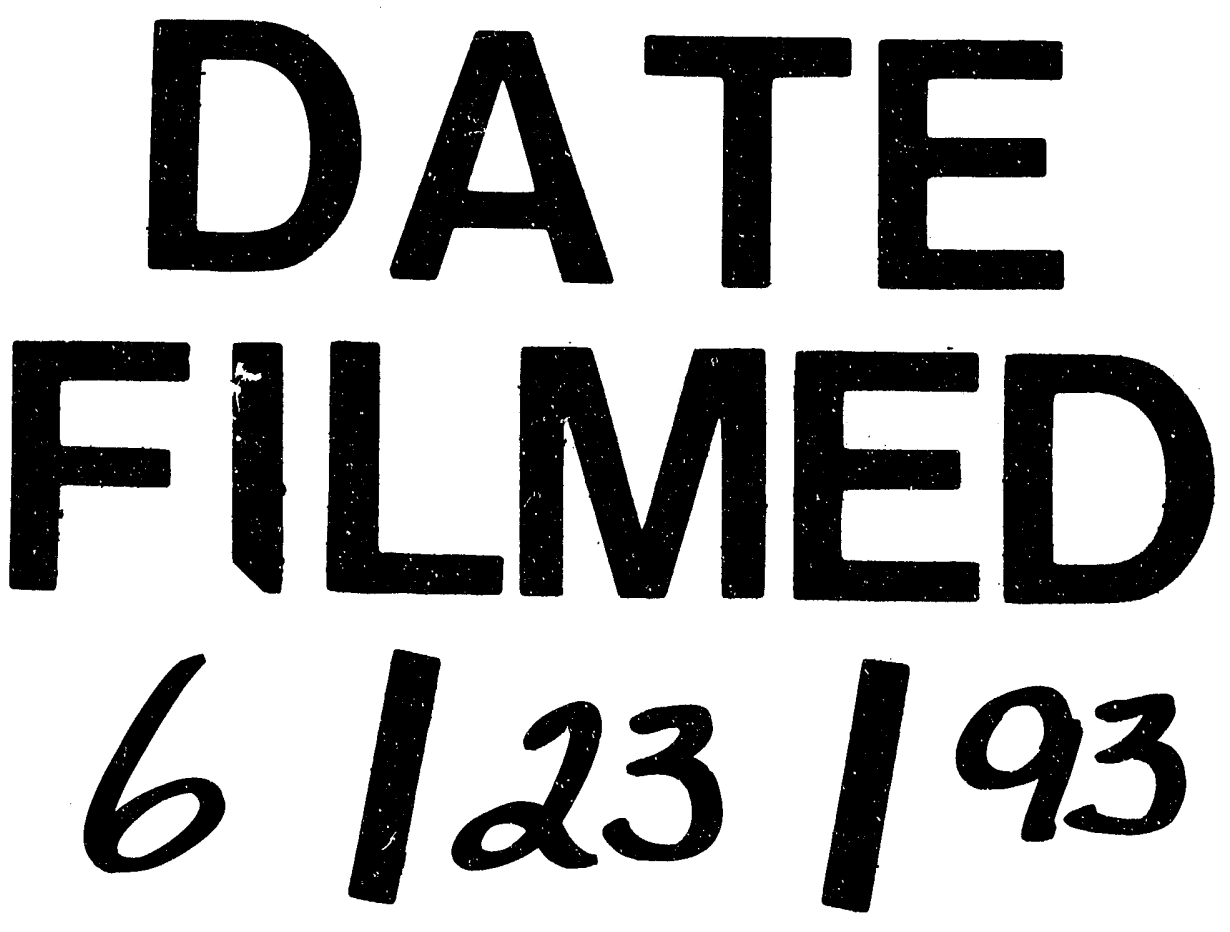
